\title{
The Carpal Tunnel Syndrome and the Double Crush Syndrome Hypothesis: Revisited
}

\author{
HEBA RAAFAT, M.D.*; AMIRA A. LABIB, M.D.* and MOHAMED R.A. SALEH, M.D.** \\ The Departments of Clinical Neurophysiology Unit*, Faculty of Medicine, Cairo University and Orthopaedic Surgery**, \\ Helwan University, Egypt
}

\begin{abstract}
Background: The commonest application of the double crush hypothesis is its association to median nerve entrapment at the wrist. The double crush concept has gained popularity because it provides a reason to evaluate the cervical spine and roots when treating carpal tunnel syndrome (CTS). It is more likely for CTS to occur as DCS rather than occurring by itself. Up to $90 \%$ of CTS patients are misdiagnosed, whereas only $10 \%$ have the problem at their wrists.
\end{abstract}

Aim of Study: To examine the validity of DCS hypothesis in CTS patients, to support or disregard the theory.

Patients and Methods: This study was conducted on 80 patients; 40 patients claiming failed carpal tunnel release operation (Group I) and 40 cases presenting with brachialgia (Group II). Diagnostic work up included neurological examination, Phalen test, Tinel sign, electromyographic examination (EMG) and nerve conduction studies (NCS) and cervical MRI Group I patients had undergone the EMG and NCS at our laboratory pre and post operatively.

Results: EMG and NCS showed 10 cases with CTS (25\%), $20(50 \%)$ with DCS and $10(25 \%)$ with cervical radiculopathy in group I, while group II patients showed 10 cases $(25 \%)$ with CTS and $30(75 \%)$ with DCS. In all patients, 50 cases (62.5\%) showed DCS. On comparing the EMG and NCS preoperative results of Group (I), with their postoperative follow-up results, there was a high statistically significant difference ( $p$-value $<0.001)$ with 34 cases $(85 \%)$ who showed improvement of the NCS results, while 6 cases (15\%) deteriorated postoperatively. There was a high statistically significant difference between both; CTS and DCS ( $p$-value $<0.001$ ), denoting a positive correlation between the two syndromes.

Conclusion: The DCS hypothesis was supported, while the concept of frequent failure of CTS release surgery was not supported for the benefit of DC hypothesis.

Key Words: Carpal tunnel syndrome - Double crush syndrome - Electrophysiological studies - Cervical radiculopathy.

Correspondence to: Dr. Heba Raafat, E-Mail: heba.raafat@kasralainy.edu.eg

\section{Introduction}

DCS has usually meant "Compression of an axon at one location makes it more sensitive to effects of compression in another location, because of impaired axoplasmic flow" (Upton and McComas) [1]. Similarly, Mackinnon [2] mentioned that "Local damage to a nerve at one site along its course may sufficiently impair the overall functioning of the nerve cells so that they become more susceptible than would normally be the case to trauma at other sites".

The most common application of the double crush hypothesis is the association of median nerve entrapment at the wrist, which is the most common entrapment among entrapment neuropathies, with proximal cervical root compression. The double crush concept has gained some popularity among chiropractors because it seems to provide a rationale for evaluating the condition of the cervical spine and roots when treating CTS (Leahy) [3]

Theories for DCS included connective tissue changes that may lead to soft tissue degeneration at both wrist and cervical spine or upper extremity weakness and pain in patients with cervical radiculopathy can cause changes in the biomechanics and patterns leading to increased upper extremity edema and consequently increased carpal tunnel pressure. Another mentioned theory is common extrinsic factors involving mechanical stress to the cervical spine that might simultaneously lead to
Abbreviation:
CTS : Carpal tunnel syndrome.
DCS : Double crush syndrome.
EMG : Electromyography.
NCS : Nerve conduction studies.
MUPs : Motor unit potentials.
SPSS : Statistical Package for the Social Sciences. 
accelerated spondylosis and evident entrapment syndrome (Murray-Leslie and Wright; Bednarik and colleagues; Pecina and colleagues) $[4,5,6]$.

The DCS is often seen in clinical practice. The two conditions occur together more than would be likely of CTS to occur alone. Up to $90 \%$ of all CTS patients are misdiagnosed. Only $10 \%$ of all CTS patients have the problem in their wrist (Russell) [7].

The DCS explains why some CTS patients have pain in the forearm, elbow, upper arm, shoulder, chest and upper back. Moreover, it explains the claims of failed attempts at surgical release by many patients when neither the surgery nor the CTS diagnosis was faulty or wrong (Upton and McComas) [1]

The existence of DCS is still debatable and controversial. Some authors suggested low incidence of DCS and others, especially recently suggested much higher percentages. However, the relationship has not been definitively explained. All the present literature and studies about the DCS are assumptions and speculations without an exact solid cellular and neurophysiological basis (Upton and McComas; Mackinnon; Russell) [1,2,7]

This study aimed at examining the validity of DCS hypothesis in CTS patients, to support or disregard the theory.

\section{Subjects and Methods}

This is a cross sectional study conducted on 80 adult patients divided into two groups; Group I included 40 patients claiming failed carpal tunnel release operation and Group II included 40 cases presenting with brachialgia.

They were referred to the Clinical Neurophysiology Unit of Kasr Al-Aini Hospital from the Neurology, Orthopedic, Rheumatology, General Surgery and Neurosurgery Departments from the period of January 2017 to December 2017.

The age of the patients ranged from 20 to 60 years. They presented with upper limb symptoms, with or without neck pains. Patients with conditions contraindicating MRI such as pregnant females, patients with history suggestive of any other neurological illness and those with chronic systemic disease or connective tissue disorder were excluded.

The used EMG machine was the Dantec machine software version 1.6 (made in Denmark) Model (Key point). Parameters for motor nerve conduction studies included sweep $5 \mathrm{msec} / \mathrm{div}$, sensitivity $1000 \mu \mathrm{v}$, stimulus duration $0.2 \mathrm{msec}$, stimulus frequency $1 \mathrm{~Hz}$, high frequency filter $10 \mathrm{kz}$, and low frequency filter $5 \mathrm{~Hz}$. Parameters for sensory nerve conduction studies included sweep 2$5 \mathrm{msec} / \mathrm{div}$, sensitivity $10 \mu \mathrm{v}$, stimulus duration $0.2 \mathrm{msec}$, stimulus frequency $1 \mathrm{~Hz}$, high frequency filter 10kz, and low frequency filter $2 \mathrm{~Hz}$. The EMG parameters included gain $50 \mathrm{~N}$ erertical division, monitor time $0.2 \mathrm{sec}$ and pass $(0.1-50 \mathrm{~Hz})$ value of low and high cuts respectively.

Diagnostic workup included history taking, neurological examination, Phalen test, Tinel sign and cervical MRI. Also motor and sensory NCS were carried out pre and postoperative for group (I) patients and only once (on referral) for group (II) patients, while EMG examination for the abductor pollicis brevis muscle, was done only for patients first diagnosed as severe CTS by NCS examination, according to the guidelines grading criteria of the Clinical Neurophysiology unit of Kasr Al-Ainy Hospital (2017).

The guidelines grading criteria of the Clinical Neurophysiology unit of Kasr Alainy hospital stated the diagnosis of early CTS when abnormal findings are only seen on comparative studies mainly with the ulnar nerve $(>0.5 \mathrm{~ms})$, mild CTS when the peak latency of the sensory studies is $>3.5$ with preserved amplitude, and the stimulating distance is $13 \mathrm{~cm}$, moderate CTS when abnormal sensory studies and prolonged distal motor latency are found, and severe CTS if any of the aforementioned NCS are found with evidence of axonal loss as defined by either an absent sensory response or absent or lowamplitude CMAP (less than $2 \mathrm{mv}$ ), or a needle EMG examination showing fibs or positive sharp wave potentials at rest or neurogenic MUPs on mild volitional activity.

EMG examination of the cervical radicles was carried out according to the recommendation of Narayanaswami [8] by evaluation of the cervical roots via examining two muscles supplied by the same root but different peripheral nerve supply. This included evaluation of C5, 6 innervated muscles by examining the deltoid and biceps brachii muscles, $\mathrm{C} 7$ by examining triceps brachii and pronator teres muscles and $\mathrm{C} 8$, $\mathrm{T} 1$ roots by examining the first dorsal interosseus and extensor indices proprius muscles.

Their study recommended motor NCS to detect any axonal loss by CMAP drop of amplitude indicating the severity of the cervical radiculopathy 
through examination of all nerves supplied by the corresponding root innervated muscles.

Sensory NCS recommended by Narayanaswami [8] included median sensory NCS of thumb for examining C5, 6 roots, 3 rd digit for examining C7 root and 5 th digit for examining $\mathrm{C} 8, \mathrm{~T} 1$. Preganglionic lesion is diagnosed nd cervical radiculopathy was confirmed if the corresponding sensory NCS were normal.

\section{Statistical analysis:}

Data were coded and entered using the statistical package for the Social Science (SPSS) version 25 IBM, USA; 2017 [9]. Data was summarized using mean and standard deviation for quantitative variables and frequencies (number of cases) and relative frequencies (percentages) for categorical variables. Comparisons between groups were done using unpaired $t$-test (Chan, 2003a) $\left[\mathbf{1 0}_{2}\right.$. For comparing categorical data, Chi square $\left(\chi^{2}\right)$ test was performed. Exact test was used instead when the expected frequency is less than 5 (Chan, 2003b) [11]. $p$-values less than 0.05 were considered statistically significant.

\section{Results}

The age of the patients ranged from 20-60 years with a mean of $36.78 \pm 7.75$. These were 56 female patients $(70 \%)$ and 24 males (30\%). Sixty-five patients $(81.25 \%)$ were complaining of numbness in the hand, especially during sleep causing patients' awakening and 25 patients (38.46\%) complained of diminished sensation after a long period of numbness. Fourty-six patients (70.77\%) out of the previously mentioned 65 reported dull-aching pain in the arm and forearm. Out of the remaining 15 patients (18.75\%), 9 patients (11.25\%) were complaining of severe hand weakness, and the other 6 (7.5\%) presented with evident hand muscles wasting in addition to weakness.

Neurological examination showed weak hand grip in 65 of the studied patients $(81.25 \%)$, and normal hand grip in 15 patients $(18.75 \%)$, diminished sensation in 42 patients $(52.5 \%)$ and normal sensory examination in 38 patients $(47.5 \%)$. Out of the 42 patients with diminished sensation, 31 patients $(73.68 \%)$ showed diminished dermatomal sensation, while 11 cases $(26.32 \%)$ showed diminished sensation of the median supply area. Fortysix patients $(57.5 \%)$ showed either positive Phalen test or Tinel sign. There were abnormal cervical MRI results in 35 of cases (43.75\%), as shown in Table (1).
Table (1): Neurological, clinical and cervical MRI data of all patients.

\begin{tabular}{lcc}
\hline $\begin{array}{l}\text { Complete neurological } \\
\text { examination }\end{array}$ & $\begin{array}{c}\text { Number of } \\
\text { patients } \\
(\mathrm{N}=80)\end{array}$ & $\begin{array}{c}\text { Percentage } \\
(\%)\end{array}$ \\
\hline $\begin{array}{l}\text { Motor power: } \\
\text { Weak hand grip }\end{array}$ & 65 & 81.25 \\
$\quad$ Normal hand grip & 15 & 18.75 \\
Sensory examination: & & \\
$\quad$ Normal & 38 & 47.5 \\
$\quad$ Diminished sensation & 42 & 52.5 \\
$\quad$ Diminished dermatomal & 31 & 73.68 \\
$\quad$ sensation & 11 & 26.32 \\
$\quad$ Diminished sensation of & & \\
$\quad$ median supply area & & 57.5 \\
Phalen test or tinel sign: & 46 & 42.5 \\
$\quad$ Positive & 34 & \\
Negative & & 43.75 \\
Cervical MRI results: & 35 & 56.25 \\
Abnormal imaging results & 45 & \\
Normal imaging results & &
\end{tabular}

All studied patients showed 20 cases with isolated CTS (25\%), 50 cases with DCS (62.5\%) and 10 cases with cervical radiculopathy solely $(12.5 \%)$.

Grading results of all studied CTS patients; Group I (preoperative), and Group II showed 30 cases with mild CTS (37.5\%), 41 cases with moderate degree $(51.25 \%)$ and 9 cases $(11.25 \%)$ with severe degree. There were no patients diagnosed as early CTS. Each of the two groups classification results are demonstrated in Table (2).

Table (2): Electrophysiological grading results of CTS among studied patients.

\begin{tabular}{lccccccl}
\hline & $\begin{array}{c}\text { Group I } \\
\text { (Preoperative) }\end{array}$ & \multicolumn{2}{c}{ Group II } & \multicolumn{3}{c}{$\begin{array}{c}\text { All studied } \\
\text { patients }\end{array}$} \\
\hline & \multicolumn{2}{c}{$(\mathrm{N}=40)$} & $\%$ & $(\mathrm{~N}=40)$ & $\%$ & $(\mathrm{~N}=80)$ & $\%$ \\
\hline Early degree & 0 & 0 & 0 & 0 & 0 & 0 \\
Mild degree & 2 & 5 & 28 & 70 & 30 & 37.5 \\
Moderate degree & 32 & 80 & 9 & 22.5 & 41 & 51.25 \\
Severe degree & 6 & 15 & 3 & 7.5 & 9 & 11.25 \\
\hline
\end{tabular}

On comparing the preoperative results of the NCS and EMG of Group (I) with their postoperative follow-up results, there was a high statistically significant difference ( $p$-value $<0.001)$ showing marked improvement after the CTS release operation, as follows; 34 cases ( $85 \%$ ) improved by EMG and NCS; 32 cases $(94.12 \%)$ changed from mild and moderate degrees of CTS to normal motor values and only 2 patients $(5.88 \%)$ changed from severe to moderate degree, whereas 6 patients $(15 \%)$ showed deteriorated results (Table 3 ). 
Table (3): Comparison of NCS results in Group (I) before and after carpal tunnel release operation.

\begin{tabular}{lllll}
\hline & \multicolumn{2}{c}{ Group I } & \\
\cline { 2 - 3 } & $(\mathrm{N}=40)$ & $\%$ & \\
& 34 & 85 & \\
\hline Improvement of NCS results & 6 & 15 & \\
Deterioration of NCS results & & & \\
Improvement $(N=34)$ : & 32 & $94.12<$ & $<0.001$ \\
$\quad$ From mild/moderate to normal & 32 & 5.88 & \\
$\quad$ From severe to moderate degree & 2 & &
\end{tabular}

Deterioration of EMG results appeared in the form of fibs or positive sharp wave potentials at rest, and/or neurogenic MUPs on mild volitional activity, together with absent CMAP responses of median NCS in $2(5.88 \%)$ out of the 6 deteriorated patients, which matches the finding during surgery of scar tissue in the carpal tunnel in $1(2.94 \%)$ case, and formation of palmar cutaneous neuroma in $1(2.94 \%)$ case. Small median CMAP amplitude (axonal loss) in 4 of them (94.12\%), which matched the finding of incomplete release of the transverse carpal ligament in $2(5.88 \%)$ patients, and inflammatory tenosynovitis in $2(5.88 \%)$ cases during the carpal tunnel release surgery.

On comparing the electrophysiological results of the isolated CTS and DCS, there was a high statistically significant difference between both ( $p$-value $<0.001)$, denoting a positive correlation between the two syndromes (Fig. 1). Another statistically positive correlation was found between the DCS diagnosis and brachialgia ( $p$-value $<0.021)$. Also a highly positive statistical significance was found between the EMG results of radiculopathy and CTS ( $p$-value $<0.001)$. However, there was no statistical significance between the EMG findings of DCS and cervical MRI results $(p$-value $>0.146)$.

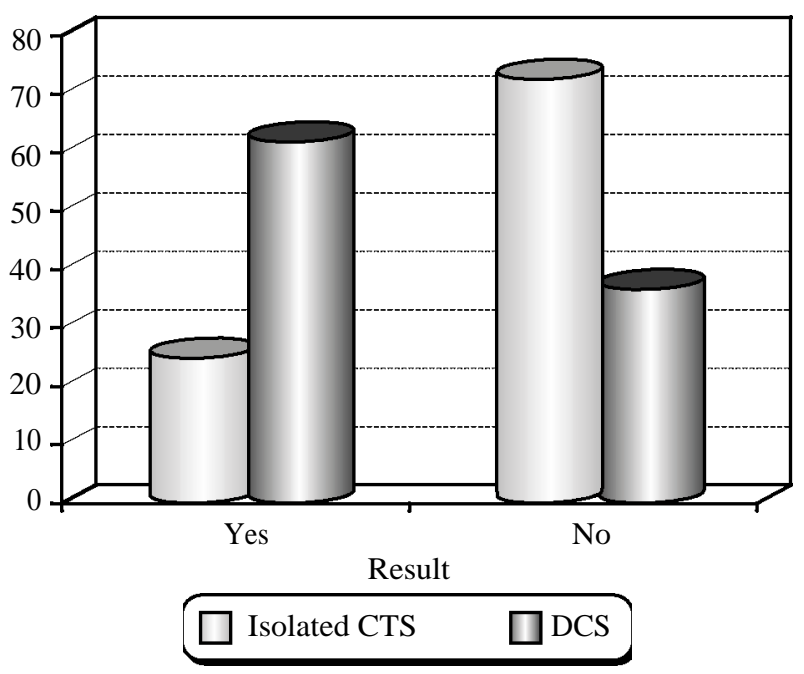

Fig. (1): Correlation between isolated CTS and double DCS.

\section{Discussion}

The compression of a nerve axon at one location makes it more sensitive to effects of compression in another location, because of impaired axonoplasmic flow. Based on this fact, Upton and McComas [1] raised the hypothesis of the "Double crush syndrome". An example of this theory is the coexistence of C6 radiculopathy and CTS which was studied by Upton and McComas [12]

In general, the incidence of double crush in patients with definite CTS has tended to be lower than that suggested, whereas, some authors found its existence in much higher percentages as $83 \%$ of the patients studied by Flatt [13]. It has gained popularity among chiropractors like Russell [7] because it seems to provide a rationale for evaluating the cervical spine when treating CTS.

In this study, the aim was to examine the validity of DC hypothesis in CTS patients to support or disregard the theory. The mean age of the studied patients was $36.78 \pm 7.75$ years. This was more or less consistent with the studies of many other authors as Radhakrishnan and colleagues, Salemi and colleagues $[14,15]$ respectively, and who stated that double crush syndrome existed in subjects aged 40 or more and specifically females. The percentage of females in this study was $70 \%$ and that of males was $30 \%$. This went in agreement with many studies for CTS and DCS suggesting female predominance in both conditions (Golovchinsky; Kwon and colleagues) [16,17]

The present study stated that 65 patients $(81.25 \%)$ out of the total number were complaining of sensory manifestations especially during sleep causing patients' awakening. Out of these, 25 patients $(38.46 \%)$ had diminished sensation after a long period of numbness. This agrees with Mackinnon [2] who concluded that the main symptom of CTS patients is usually numbness.

The current study showed a positive statistical correlation between the electrophysiological diagnosis of DCS and patients complaining of brachialgia ( $p$-value $<0.021)$. This finding matched the study by Morgan and Wilbourn [18] supporting the DC theory, and who had often defined cervical radiculopathy whether by symptoms or by radiological evidence. Although their results matched the current study results, their strategy was inaccurate, as they concluded their results depending on the patients' symptoms or radiological findings that showed only anatomical abnormalities but not functional ones. 
This study believes that electrophysiological techniques are more reliable and precise means for identifying cervical radiculopathy and CTS, as it measures the functional aspect rather than the anatomical, a belief supported by Kwon and colleagues [17].

According to the neurophysiological results, the percentage of isolated CTS patients in the current study was $25 \%$, that of DCS was $62.5 \%$ and that of isolated cervical radiculopathy was $12.5 \%$. Out of the total number of patients, $43.75 \%$ had abnormal imaging results.

Golovchinsky [16] found that the two conditions occurred together more often than one condition alone. On the other hand, Kwon and colleagues [17] found that the frequency of electrophysiologically determined CTS and the level of cervical radiculopathy were not consistent with the DC. They noted that nerve conduction abnormalities were common but the double crush was not supported by the distribution of the abnormalities in relation to the diseased root. This study found a high statistically significant difference between isolated CTS patients and DCS patients ( $p$-value $<0.001$ ), and another highly positive significant difference between the EMG results of cervical radiculopathy and CTS ( $p$-value $<0.001$ ), denoting a positive relation between the two syndromes. This disagrees with the retrospective study conducted by Morgan and Wilbourn [18] who investigated the association between cervical radiculopathy and CTS and reported failed significant association.

These contradictory results in the incidence of DCS between many authors could be due to the fact that the exact neurophysiological and cellular mechanisms of this phenomenon is not yet clearly established and all of the present explanations are rather assumptions.

\section{Conclusion:}

The double crush hypothesis was supported by this study. It is crucial to investigate for DCS, as it is a clinically significant consideration which makes the results of treatment of patients complaining of upper limbs symptoms less predictable and often a reason for claimed failure of CTS surgery.

\section{References}

1- UPTON M., McCOMAS J.: The double crush in nerve entrapment syndromes. Lancet, 2: 359-362, 1973.

2- MACKINNON S.E.: Double and multiple "crush" syn- dromes: Double and multiple entrapment neuropathies. Hand Clin., 8: 369-90, 1992.

3- LEAHY M: Improved treatments for carpal tunnel and related syndromes. Chiro Sports Med., 9 (1): 6-9, 1995.

4- MURRAY-LESLIE F. and WRIGHT V.: Carpal tunnel syndrome, humeral epicondylitis, and the cervical spine: A study of clinical and dimensional relations. Br. Med. J., 1 (6023): 1439-1442, 1976.

5- BEDNARIK J., KADANKA Z., VOHANKA S., STEJSKAL L., VLACH O. and SCHRODER R.: The value of somatosensory-and motor-evoked potentials in predicting and monitoring the effect of therapy in spondylotic cervical myelopathy. Prospective randomized study. Spine, 24 (15): 1593-1598, 1999.

6- PECINA M.M., KRMPOTIC-NERMANIC J. and MARKIEWITZ A.D.: Tunnel syndromes: Peripheral nerve compression syndromes 3 Edition Boca Raton, FL Press, 2001.

7- RUSSELL B.S.: Carpal tunnel syndrome and the "double crush" hypothesis: A review and implications for chiropractic. Chiropr Osteopat, 16: 2, 2008.

8- NARAYANASWAMI P., GEISBUSH T., WILSGAARD T., JONES L., WEIAA M., MOZAFFAR T., GRONSETH G., et al.: Critically re-evaluating a commom technique: Accuracy, reliability and confirmation bias of EMG. Neurology, 68 (3): 218-23, 2016.

9- IBM Corp.: released. IBM SPSS Statistics for Windows, Version 25.0 Armonk, NY: IBM Corp., 2017.

10- CHAN Y.H.: Biostatistics 102: Quantitative DataParametric \& Non-parametric Tests. Singapore Med. J., 44 (8): 391-396, 2003a.

11- Chan Y.H.: Biostatistics 103: Qualitative Data-Tests of Independence. Singapore Med. J., 44 (10): 498-503, $2003 b$.

12- UPTON M., McCOMAS J.: Double crush syndrome. Orthop. Clin. North Am., 19 (1): 147-55, 1988.

13- FLATT D.W.: Resolution of a double crush syndrome. J. Manipulative Physiol. Ther., 17: 395-397, 1994.

14-RADHAKRISHNAN K., LITCHY W.J., OFALLON W.M. and KURLAND L.T.: Epidemiology of cervical radiculopathy: A population-based study from Rochester, Minnesota, 1976 through 1990. Brain, 117 (2): 325, 1994.

15- SALEMI G., SAVETTIERI G., MENEGHINI F., Di BENEDETTO M.E., RAGONESE P., MORGANTE L., et al.: Prevalence of cervical spondylotic radiculopathy: A door-to-door survey in a Sicilian municipality. Acta. Neurol. Scand, 93 (23): 184-8, 1996.

16- GOLOVCHINSKY V.: Double-Crush Syndrome in Upper Limbs. Double Crush Syndrome,pp 113-129, 2000.

17- KWON H., HWANG M. and YOON D.: Frequency and severity of carpal tunnel syndrome according to level of cervical radiculopathy: Double crush syndrome? Clinical Neurophysiology, 117: 1256-1259, 2006.

18- MORGAN G. and WILBOURN A.J.: Cervical radiculopathy and coexisting distal entrapment neuropathies: Double-crush syndrome? Neurology, 50: 35-9, 1998. 


\section{متلازمة التفق الرسغى ونظرية السحق المزدوج : إعادة نظر ونظر الري}

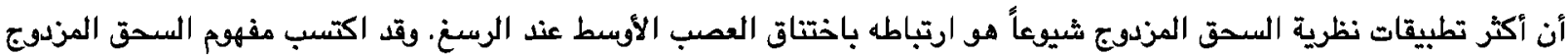

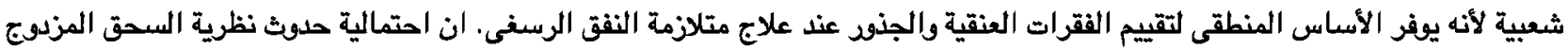

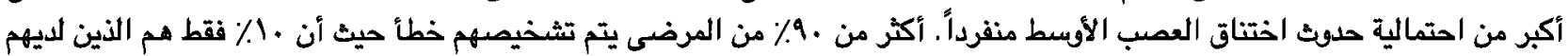
مشكلة عند الربنغ فقط.

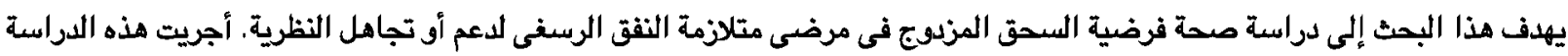

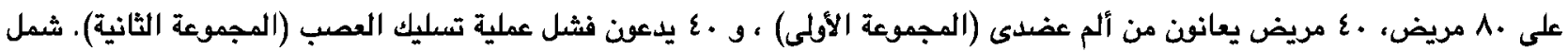

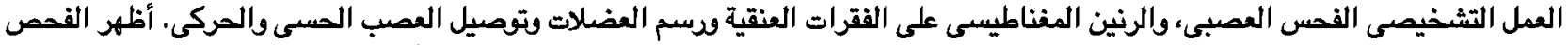

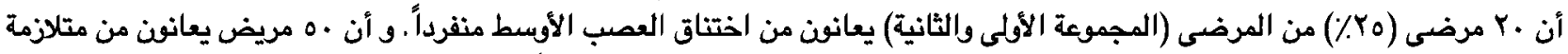

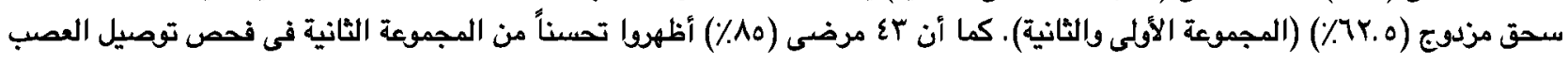
بعد التدخل الجراحى.

نستنتج من ذلك أن هذه الدراسة تؤيد نظرية السحق المزدوج بينما لا تعتمد مفهوم الفشل المتكرر لعملية تسليك العصب الجراحى. 